DOI https://doi.org/10.18551/rjoas.2018-09.49

\title{
OPERATIONAL STRATEGY ANALYSIS USING LEAN SIX SIGMA AT PT. FOUR JAFFEE INDONESIA
}

\author{
Ramdhani Dadan \\ Faculty of Economics and Business, University of Sultan Sugeng Tirtayasa, Indonesia \\ Firdauz Frequencia Sukmana \\ Faculty of Economics and Business, University of Esa Unggul, Indonesia \\ *E-mail: ddn ramdhani@yahoo.com \\ ORCID: 0000-0001-6799-7405
}

\begin{abstract}
Coffee is a type of drink that is popular with the public. Consumers buy coffee is usually due to customs and bigotry consumers with coffee that they often consume daily. Various product brands offer their respective advantages embodied in the attributes inherent in a product such as flavor, aroma, color, packaging, fill capacity, price, etc. thus generating differences between brands. Coffee is one product that has many competitors. This study aims to analyze the operational strategies undertaken by PT. Four Jaffee Indonesia. Implementation of operational strategy is needed in running the company in order to continue to run against business competition. Companies are required to set annual goals, create policies, motivate employees, and allocate resources, so strategy strategies that have been formulated can be run. The implementation of the strategy includes the development of a supportive culture in the strategy of creating an effective organizational structure, redirection of marketing efforts, budget preparation, development and utilization of information systems and association of employee competency with organizational performance.
\end{abstract}

\section{KEY WORDS}

Operational strategy, coffee, business, company.

Coffee is a type of drink that is popular with the public. Consumers buy coffee is usually due to customs and bigotry consumers with coffee that they often consume daily. In attracting the attention of consumers, manufacturers strive to produce quality products. Different brands of products offer their respective advantages embodied in the attributes embedded in a product such as flavor, aroma, color, packaging, fill capacity, price, and so as to create a distinction between brands. Coffee is one product that has many competitors.

There are several coffee products with various brands and variety of packaging forms sold in traditional markets. Coffee brands are widely circulated in the market, among others brands Ship Fire, Top, ABC and many more brands of coffee sold in modern and traditional markets. The number of brands of coffee that exist in the market will bring consumer behavior to the differences between brands. There are many consumers consuming coffee for various reasons based on the attributes that exist in the coffee itself. Coffee attributes include (i) a sense of pleasure for the consumer; (ii) aroma, not all coffee has an aroma, coffee consumers are usually happy to consume coffee that has a fragrant aroma because it can increase the pleasure when consuming it; (iii) packaging and packaging design, coffee packaging made of aluminum foil is considered to be easy to open if it is to be consumed and the design of packaging with various design colors makes its own interest for coffee consumers, and (iv) the relatively affordable price, the tendency of low involvement (low involvement) consumer behavior, characterized by decision making that does not require much consideration, meaning the consumer without having to think long to buy because of the cheap price of coffee, (Hashimoto, et al., 2004).

However, it is not automatically possible for consumer behavior in purchasing Coffee low involvement (low involvement). David (2012) suggests that strategy is a common tool 
with a long-term goal to be achieved. Business strategy includes geographic expansion, diversification, acquisition, product development, market penetration, knowledge, divestiture, liquidation and joint venture. Strategy is the implementation plan of a company. The plan provides a framework for managerial decisions. And the main aspect of the corporate environment is industry. A company must strive to achieve sustainable competitive advantage in the form of (i) continue to adapt to change in external trends and internal capacity, capabilities and resources; and (ii) effective planning, implemetation, and evaluation of strategies that play a major role (Teece, 2010).

According to David (2012) also suggests that the strategy manajement consists of three stages, namely: Strategy formulation, Implementation strategy, and assessment strategy. Strategy formulation includes vision and mission development, identification of external opportunities and threats, awareness of internal strengths and weaknesses, setting long-term goals, searching for alternative strategy strategies, and selecting specific strategies to achieve goals.

Implementing a strategy requires companies to set annual goals, create policies, motivate employees, and allocate resources, so strategy strategies that have been formulated can be run. The implementation of the strategy includes the development of a supportive culture in the strategy of creating an effective organizational structure, redirection of marketing efforts, budget preparation, development and utilization of information systems and association of employee competency with organizational performance.

Strategy assessment is the last step in strategic management, where a good manager should know whether the strategy is effective or not. Strategy assessment is the main way to know this kind of information. All open strategies to be modified in the future can then be adapted to various factors, whether internal or external factors constantly changing, (Bröder and Schiffer, 2003). In carrying out its operational strategy, management establishes some of the company's values that will be the spirit in all activities and that must be undertaken by all components within the organization. The values are: (i) customer centric "meet customer expectation", (ii) integrity "walk the talk", (iii) behave discipline and obedience, (iv) nationalism "national pride", (v) continue to grow and compete, (vi) togetherness and respect for others, (Allayannis, et al., 2001).

Framework of study. Operation is a function or system that transforms the input into output with a higher value. The operation process is a series of value chain activities that extend from suppliers to distributors. The operational strategy of converting inputs to outputs by using physical resources, so as to satisfy customers' satisfaction while meeting organizational goals related to effectiveness, efficiency and adaptability to business needs.

The operational function will pay particular attention to the conversion process using physical resources, and can be translated into several activities in the operations management function ie product design, site selection, layout selection, poses design, inventory, maintenance, scheduling, quality planning, purchasing. At the operational strategy, the frame work to be used, adapted to combine the theory and needs of the business plan, by combining it with lean six sigma approach, to improve operational acuity.

Product design. Product design is a process whereby converting from idea to idea, so in this process every business organization should be able to design, develop and introduce new products as a strategy to survive, grow and develop new products. The product to be launched is the biggest handset faced by the organization / company. So the whole process of identifying the need to physically produce must be considered, from design and marketing, product, development and manufacturing process. Product development will be translated from customer needs given by the marketing team, then this becomes a technical specification and design a variety of features. Manufacturer has the responsibility to choose the process in which the product can be produced.

PT Four Jaffee Indonesia in Business start-up phase will focus on 1 type of product preparation that is effervescent coffee. Effervescent coffee is a type of product preparation that offers, a unique type of presentation, as well as can improve the taste. For coffee beans used, it is standardized SNI 01-2907-2008 and meet the general requirements and special requirements as stated in the $\mathrm{SNI}$. In designing the product is not required three phases 
according to Prasetya and Lukiastuti (2009), namely: Functional design, Industrial design, Design for manufacturability.

Six main functions of packaging that should be met by a packaging material, namely: First, Keep food products or agricultural products to stay clean and protected from dirt and contamination. Second, protect food from physical damage, changes in water content and irradiation. Third, it has the ease of opening or closing, and also facilitates in the stages of handling, transportation and distribution. The four have functions that are both efficient and economical, safe for the environment. Fifth has the size, shape and weight according to existing norms or standards, easy to dispose and easily molded or molded. Sixth, show identification, information, attractiveness and clear appearance so as to help the promotion or sale.

Packaging should also be friendly to the environment, whether viewed from the packaging materials used, the way of packing materials, the operation and packaging waste. ISO 14000 guidelines concerning the environment are closely related to packaging. The benefits of food storage include 3 main things, namely: Maintaining or reducing quantitative loss or loss of weight (volume), Maintaining a qualitative shrinkage or maintaining the quality of food to meet the existing quality standards, have good nutritional value, safe to eat and does not cause any acute or chronic health problems. As well as Maintaining the economic value of stored food products.

Preparation of business establishment. In the establishment of Coffee Effervescent business, starting with the establishment of PT Four Jaffee Indonesia, and of course in the process of establishing this company, will follow the applicable regulations, as stated in the Indonesian republic law no. 40 of 2007 concerning limited liability company. The filing of this company name is registered by a notary through Ministry Of Law And Human Rights Legal Entity Administration System (Sisminbakum) through online system. The making of the deed of establishment is conducted by a notary authorized in all regions of the Republic of Indonesia to further obtain approval from the Ministry Of Law And Human Rights.

Furthermore, in the process of making the deed of establishment of the company, the prospective founder of the company is asked to name the founder of the company which minimum consists of 2 people. Basically, Permenkumham no. 4/2014 stipulates that any approval or rejection by Ministry Of Law And Human Rights is submitted electronically to the request. To that end, the notary can print his own decision from the Ministry Of Law And Human Rights. In the event that the applicant is obliged to submit supporting documents in submitting a request, the applicant is required to submit an electronic statement declaring that the supporting documentation is complete.

However, such documents in the physical form shall be deposited by a notary. This is different from Permenkumham no. 01/2011, which requires the applicant to physically submit a letter of application accompanied by supporting documents. The new regulation will speed up the issuance of the Decree of PT Four Jaffee Indonesia Incorporation Deed Establishment from the Minister of Law and Human Rights of the Republic of Indonesia. Certificate of Business Domicile or in short SKDP is a Letter explaining Domicile of a business entity, in this case Small and Medium Enterprises (SMEs).

SMEs here is a term that refers to the type of Small Business with a maximum net worth of Rp 200,000,000, excluding land and building business premises. While classified as small business itself, according to Presidential Decree No. RI. 99 Year 1998, is a small-scale economic activity with a business field that the majority are small business activities and need to be protected to prevent unfair business competition. Other things that need to be prepared in the establishment are: business company domicile certificate, company NPWP, permit of disturbance, trade license, trademark registration, brand registration, environmental clearance process, brand and logo.

Selection of company location. PT Four Jaffee Indonesia is located in Bizlink warehousing and industry area, located in the administrative area of Sukamulya Urban Village, Cikupa Subdistrict, Tangerang Regency, Banten Province. The selection of this location to pay attention to the factors that affect the determination of the location for the company to operate smoothly, efficiently and effectively. 
BizLink Tigaraksa, Tangerang which is an integrated business center area with warehouses, offices, shophouses and residential presidential residential areas. It is part of the BizLink development of integrated areas in which there are residential projects, multipurpose and commercial buildings with total development area covering 100 hectares. PT Four Jaffee Indonesia location does not disturb the existence of the surrounding community because by the developer, PT Ciputra has been arranged in such a way and integrated well. Company locations are selected based on several considerations, including: (i) a supportive community environment; (ii) close to the market; (iii) ease of obtaining raw materials, (iv) supportive transport facilities, (v) skilled labor; (vi) Energy Source; (vii) an easy source of water; (viii) non-extreme climate, (ix) favorable investment situation.

Operational management. The selection of management systems with Lean Six Sigma is a distinct advantage over other industries. Achieving good production process by applying good and correct industrial hygiene to achieve profit and operational spirit with Process excellence. After preparing pre operational then PT Four Jaffee Indonesia will prepare the operational process to run efficiently, effectively and generate profit for the company.

Lean Six Sigma is a continuous improvement methodology that combines DMAIC (Define, Measure, Analyze, Improve, Control) processes and statistical analysis tools from Six Sigma and combines it with lean manufacturing tools to significantly eliminate or reduce 8 types of waste ) as losses (looses) in the value stream, trying to cause the loss to zero. Lean Six Sigma is a process that aims to process $6 \sigma$ (sigma).

The six sigma process is a process in which 3.4 defects occur per million opportunities / Defects per Million Opportunities (DPMO). Two important steps in Lean Six Sigma to measure variation are mean and standard deviation. One of the most important measures in Lean Six Sigma is Sigma, or standard deviation. Sigma is used as a metric to measure variations in processes. The tighter the variation, the higher the quality of the process.

Lean's main principle is the down-line improvement through waste elimination in value streams, waste as identified by the customer. Value-added activities are activities that customers are willing to pay for all other activities, classified as non- Value added is a waste of money. What customers want to pay for a work is a plus on a product, service, or unit. Activities that turn raw goods into finished goods. Non-value added activities consist of eight types of waste, which can be abbreviated as DOWNTIME: Defects, Over-production, Waiting, Non-utilized Resources / Talent, Transportation, Inventory, Motion, Excess Processing.

Lean Six Sigma is a continuous improvement methodology that combines DMAIC (Define, Measure, Analyze, Improve, Control) processes and statistical analysis tools from Six Sigma and combines it with lean manufacturing tools to significantly eliminate or reduce 8 types of waste ) as losses (looses) in the value stream, trying to cause the loss to zero. Lean Six Sigma is a process that aims to process $6 \sigma$ (sigma).

Table 1 - Six Sigma Level

\begin{tabular}{|c|c|c|c|}
\hline Tingkat sigma & DPMO & Cpk & \% Yield \\
\hline $6 \sigma$ & 3,4 & 2,0 & 99,99966 \\
\hline $5 \sigma$ & 233 & 1,67 & 99,98 \\
\hline $4 \sigma$ & 6.210 & 1,33 & 99,38 \\
\hline $3 \sigma$ & 66.807 & 1,00 & 93,3 \\
\hline $2 \sigma$ & 308.537 & 0,67 & 69 \\
\hline $1 \sigma$ & 690.000 & 0,33 & 31 \\
\hline
\end{tabular}

The six sigma process is a process in which 3.4 defects occur per million opportunities / Defects per Million Opportunities (DPMO). Two important steps in Lean Six Sigma to measure variation are mean and standard deviation. One of the most important measures in Lean Six Sigma is Sigma, or standard deviation. Sigma is used as a metric to 
measure variations in processes. The tighter the variation, the higher the quality of the process. A process is said to be a Six Sigma process if six standard deviations can fit between each of the process mean sides and customer specifications. This is equivalent to Cpk $=2.0$.

Lean's main principle is the down-line improvement through waste eradication in the value stream, waste as identified by the customer. Value-added activities are activities that customers are willing to pay for all other activities, classified as non- Value added is a waste of money. What customers want to pay for a work is a plus on a product, service, or unit. Activities that turn raw goods into finished goods. Non-value added activities consist of eight types of waste, which can be abbreviated as DOWNTIME: Defects, Over-production, Waiting, Non-utilized Resources / Talent, Transportation, Inventory, Motion, Excess Processing.

The define stage is the step in determining the problem and giving the restriction of the improvement activity. At this stage, identification of production process and identification from value chain to customer value by using SIPOC (Supplier-Input-Process-Output-Customer) analysis. Pt Four Jaffee Indonesia understands well and fully understands that the process (throughput) and its Improvement activity (improvement) as it is very important to understand the process in totality, Sipoc will help the owners or investors and stakeholders as well as business process actors to set the boundaries- limitations of what will be done.

There are three uses of SIPOC: (i) to provide thorough knowledge to team members unfamiliar with the related process; (ii) to reconnect the process with the people involved, (iii) to help the team define the new process. Supply chain management plays a very important role in delivering products to consumers, ranging from raw material sources to final product distribution. In this case PT Four Jaffee Indonesia leads the excellence of innovation and technology. In the supply chain process PT Four Jaffee Indonesia utilizes eight disciplines. Namely, engineering, Manufacturer, procurement, logistics, customer service, planning, quality and safety.

This stage aims to measure the production process as a whole by measuring the standard time step of each process activity by creating value stream mapping, displaying seven waste that occurs along the value stream, determining critical to waste for the most influential waste in each waste using Pareto Diagram determine DPMO and sigma level in waste defect. Value streams are all activities (both value added and non value-added) that are currently required to bring a product through the main stream that is important for each product: (i) the flow of production from raw materials to customers, and design flow from concept to launch (Rother and Shook, 2003). Value stream mapping is the goal is to throw or reduce activities which not provide added value, or so-called waste or young. The use of waste disposal methods to increase the company's competitive advantage was first initiated by Toyota's chief engineer Taiichi Ohno and sensei Shigeo Shingo. There are seven wastes generally accepted within the Toyota Production System: (i) overproduction, (ii) waiting, (iii) transporting, (iv) improper processing, (v) unnecessary Inventory, (vi) unnecessary motion, (vii) defects.

In the production context, there are three types of operations that work. These three operations can be categorized into (i) non-value adding; (ii) necessary but not providing necessary (non-value adding) value; (iii) provide value-adding (Hines and Rich, 1997).

In doing this VSM, literature from several sources is used as current state and then future state is the ideal condition expected. So in the discussion of this Chapter will only be discussed on the operational side of the company alone In using VSM a production system is not seen from one side only but viewed as a whole production system. VSM is useful for improving the running system. So it can be said the principal purpose of the VSM is to identify all waste in the production flow and try to eliminate the waste (Rother and Shook, 1999).

The production process strategy becomes the spirit of the production process that will run as well as the core of the business being developed. Because in determining the strategy of this production process will berimpact directly to the sustainability of the business, including the determination of the type of process that will be used. 
In ensuring the quality of the products produced then good quality production material that will be accepted by PT Four Jaffee Indonesia such as coffee, maltodextrin, refined sugar, PEG, milk creamer, citric acid and sodium bicarbonate. From the incomming process, afterwards will be sent to dispensing that is the initial process of making batch material in accordance with the production work order that has been given by the planner team. After that will enter the drying area (wet granulation and dry granulation) the output of this process is the material into a small branular granule which will then go into the process of mixing with acid base before the process of tableting, the process of tableting, granule material will be printed in accordance with size and size of the desired product, before then going through the packing process.

The purpose of the analysis stage is to verify the causes that affect key inputs and key outputs. Stages of analysis:

- Determine the critical input. Determining where problems occur in a process;

- Conducting data analysis and process analysis. At this stage an analysis of the data has been obtained and the process that occurs in more detail. This stage aims to know what the root cause of the actual problem;

- Determining the root cause of the problem. Determining the root causes of problems that occur in the process is done for every problem that occurs;

- Prepare the root cause priority of the problem. One problem can have several causes of problems. At this stage the selection of root causes that will be the target of improvement;

- Perform a review of the Analyze stage. Tools used in the Analyze stages are Failure Modes and Effects Analysis (FMEA).

Improvement is a phase in the DMAIC cycle to fix the problems that have been done define process, measure and analyze based on the data obtained. The next step is to make recommendation improvement which continued to choose the priority of improvement recommendation using Form analysis and consequence of process failure (Failure Mode and Effects Analysis) which shortened to FMEA. Phase improvement in the field is done to determine which waste will be the priorities to be given improvement recommendations. Proposed improvements to minimize waste that occurs in the production process using seven types of waste.

Lean Manufacturing is a concept of streamlining production from Japan. This concept is the concept of adoption of Toyota's production system. The concept of this approach is oriented to waste elimination (waste) that occurs in the production system. Elimination of this waste is done for the production system to run effectively and efficiently. The concept of this approach is pioneered by Taichi Ohno and Shigeo Shingo where the implementation of this concept is based on 5 principles: (i) understand the customer value; (ii) value Stream Analysis; (iii) flow; (iv) pull; (v) perfection. In lean application, waste must be eliminated. Waste is an activity that has no added value. Therefore, waste must be eliminated because it can cause the production process to be more efficient.

At control stage PT Four Jaffee Indonesia will continue to make continuous improvements by applying, Lean Six Sigma in which there are FMEA, 7 QC Tools, and so on. All of these methods will be very powerful in the field, and will greatly affect the stability of the process, so it is considered necessary to make SOP.

\section{CONCLUSION}

Operational Strategy applied to PT. Four Jaffee Indonesia starts from making product design. Before the product is designed first determine the product design and packaging design. In the establishment of Coffee Effervescent business, starting with the establishment of PT Four Jaffee Indonesia, and of course in the process of establishing this company, will follow the applicable regulations, as stated in the Indonesian republic law no. 40 of 2007 concerning limited liability company. Furthermore, in the process of making the deed of establishment of the company, the prospective founder of the company is asked to name the founder of the company which minimum consists of 2 people. Other things that need to be 
prepared in the establishment are: business company domicile certificate, company NPWP, permit of disturbance, trade license, trademark registration, brand registration, environmental clearance process, brand and logo.

Company locations are selected based on several considerations, including: (i) a supportive community environment; (ii) close to the market; (iii) easiness in obtaining raw materials; (iv) supportive transport facilities; (v) skilled labor; (vi) Energy Source; (vii) an easy source of water; (viii) the climate is not extreme; (ix) favorable investment situation. Lean Six Sigma is a continuous improvement methodology that combines DMAIC (Define, Measure, Analyze, Improve, Control) processes and statistical analysis tools from Six Sigma and combines it with lean manufacturing tools to significantly eliminate or reduce 8 types of waste as losses (looses) in the value stream, trying to cause the loss to zero.

Measure aims to measure the production process as a whole by measuring the standard time step of each process activity by creating value stream mapping, displaying seven waste that occurs along the value stream, determining critical to waste for the most influential waste in each waste using Pareto Diagram and determining DPMO and sigma level in waste defect. The purpose of the Analyze stage is to verify the causes that affect key inputs and key outputs. Stages in Analyze: (i) determine critical input; (ii) perform data analysis and process analysis; (iii) determine the root cause of the problem; (iv) prioritizing the root cause of the problem.

Improve is a phase in the DMAIC cycle to fix the problems that have been done define process, measure and analyze based on the data obtained. The next step is to make recommendation improvement which continued to choose the priority of improvement recommendation using Form analysis and consequence of process failure (Failure Mode and Effects Analysis) which shortened to FMEA. At the control stage PT Four Jaffee Indonesia will continue to make continuous improvements by applying, Lean Six Sigma in which there is FMEA, 7 QC Tools, and so on. All these methods will be very powerful in the field, and will greatly affect the stability of the process, so it is considered necessary to make SOP or standard work.

\section{REFERENCES}

1. Allayannis, G., Ihrig, J., \& Weston, J. P. (2001). Exchange-rate hedging: Financial versus operational strategies. American Economic Review, 91(2), 391-395.

2. Bröder, A., \& Schiffer, S. (2003). Bayesian strategy assessment in multi-attribute decision making. Journal of Behavioral Decision Making, 16(3), 193-213.

3. David, R. F. 2012. Strategic Management Concepts \& Cases, 14th edition. Pearson Academic.

4. Hashimoto, A., Mori, H., Kanou, M., Yamanaka, A., \& Kameoka, T. (2004). Mid-infrared spectroscopic analysis on brewed coffee characteristics. In Asian Pacific Confederation of Chemical Engineering congress program and abstracts Asian Pacific Confederation of Chemical Engineers congress program and abstracts (pp. 791-791). The Society of Chemical Engineers, Japan.

5. Hines, P, And N. Rich, 1997. "The Seven Value Stream Mapping Tools". International Journal of Operations \& Production Management, Vol. 17. Iss: 1 pp. 46 - 64.

6. Prasetya, H. dan Lukiastuti, F. 2009. Manajemen Operasi. Yogyakarta: Media Pressindo.

7. Rother, M. dan Shook, J. 1999. Learning to See. Version 1.2. Brookline, MA: Lean Enterprise Institute.

8. Rother, M. dan Shook, J. 2003. Learning to See. Lean Enterprise Institute (LEI), Cambridge Center, Cambridge.

9. Teece, D. J. (2010). Business models, business strategy and innovation. Long range planning, 43(2-3), 172-194. 